\title{
PROGRESSO GENÉTICO OBTIDO PELO MELHORAMENTO DO ARROZ DE SEQUEIRO EM 21 ANOS DE PESQUISA EM MINAS GERAIS'
}

\author{
ANTÔNIO ALVES SOARES ${ }^{2}$, PATRÍCIA GUIMARÃES SANTOS ${ }^{3}$, ORLANDO PEIXOTO DE MORAIS ${ }^{4}$, \\ PLIINIO CÉSAR SOARES ${ }^{5}$, MOIZÉS DE SOUSA REIS ${ }^{6}$ e MOACIL ALVES DE SOUZA7
}

RESUMO - Este trabalho objetivou estimar o ganho genético obtido pelo programa de melhoramento de arroz de sequeiro (Oryza sativa L.) desenvolvido em Minas Gerais cooperativamente pela Epamig/Embrapa-Centro Nacional de Pesquisa de Arroz e Feijão (CNPAF)/UFLA/UFV, no período de 1974/75 a 1994/95. Para tanto, utilizaram-se os dados dos ensaios comparativos avançados de cultivares e linhagens de arroz de sequeiro conduzidos no referido período. Em virtude da distribuição irregular de chuvas e da resposta diferenciada dos materiais de ciclos diferentes às condições climáticas, optouse por dividi-los em dois grupos; um contendo os genótipos precoces e o outro os de ciclo médio. Os resultados alcançados mostraram que ocorreu um ganho genético médio anual de $1,26 \%$ e de $3,37 \%$ em relação ao grupo precoce e ao de ciclo médio, respectivamente. O grupo precoce superou estatisticamente $(\mathrm{P} \leq 0,01)$ em produtividade de grãos o grupo de ciclo médio, indicando que em Minas Gerais deve-se dar preferência ao plantio de cultivares de ciclo curto.

Termos para indexação: Oryza sativa, ganho genético, avaliação de genótipos, cultivar.

\section{GENETIC PROGRESS OBTAINED BY UPLAND RICE BREEDING IN TWENTY ONE YEARS OF RESEARCH IN THE STATE OF MINAS GERAIS, BRAZIL}

\begin{abstract}
This work aimed to estimate the genetic gain obtained by the upland rice (Oryza sativa L.) breeding program developed in Minas Gerais State, Brazil, in cooperation with Empresa de Pesquisa Agropecuária de Minas Gerais (Epamig), Embrapa-Centro Nacional de Pesquisa de Arroz e Feijão (CNPAF), Universidade Federal de Lavras (UFLA) and Universidade Federal de Viçosa (UFV), from $1974 / 75$ to 1994/95. Results of the comparative trials of upland rice cultivars and lines conducted over the above quoted period were utilized. Because of irregular rainfall distribuition and the distinctive response of different cycles to climatic conditions, the option was to divide them into two groups, one encompassing the early genotypes and the other those of medium cycle. The achieved result showed that an average genetic gain of $1.26 \%$ and $3.37 \%$ for the early group and medium cycle, respectively, occurred. In addition, it was found that the early group statistically outyielded $(\mathrm{P} \leq 0.01)$ as to grains the medium cycle group, denoting that in Minas Gerais the short cycle cultivars should be preferred.
\end{abstract}

Index terms: Oryza sativa, genetic gain, genotypes evaluation, cultivar.

\footnotetext{
${ }^{1}$ Aceito para publicação em 31 de julho de 1998 .

${ }^{2}$ Eng. Agr., Dr., Dep. de Agricultura, Universidade Federal de Lavras (UFLA), Caixa Postal 37, CEP 37200-000 Lavras, MG. E-mail: aasoares@ufla.br

${ }^{3}$ Eng. Agr., M.Sc., Estudante de Doutorado em Genética e Melhoramento de plantas, Dep. de Biologia, UFLA. E-mail pgsantos@ufla.br

${ }^{4}$ Eng. Agr., Dr., Embrapa-Centro Nacional de Pesquisa de Arroz e Feijão (CNPAF), Caixa Postal 179, CEP 75375-000 Santo Antônio de Goiás, GO. E-mail: peixoto@enpaf.embrapa.br

${ }^{5}$ Eng. Agr., Dr., Empresa de Pesquisa Agropecuária de Minas Gerais (EPAMIG), Caixa Postal 216, CEP 36570-000 Viçosa, MG. E-mail: plinio@mail.ufv.br

${ }^{6}$ Eng. Agr., Dr., EPAMIG, Caixa Postal 176, CEP 37200-000 Lavras, MG. E-mail: epamig@ufla.br

${ }^{7}$ Eng. Agr., M.Sc., Dep. de Fitotecnia, Universidade Federal de Viçosa (UFV), CEP 36570-000 Viçosa, MG. E-mail moacil@mail.ufv.br
}

\section{INTRODUÇÃO}

O programa de melhoramento genético de arroz de sequeiro (Oryza sativa L.) de Minas Gerais vem sendo conduzido cooperativamente, desde 1974, pela Empresa de Pesquisa Agropecuária de Minas Gerais (Epamig), Embrapa - Centro Nacional de Pesquisa de Arroz e Feijão (CNPAF), e recentemente também pela Universidade Federal de Lavras (UFLA) e Universidade Federal de Viçosa (UFV). Como resultado desse esforço conjunto, foram lançadas para o Estado um grande número de cultivares, com destaque para Rio Paranaíba, Guarani, Douradão, Caiapó, Canastra e Confiança, as quais, além de proporcionarem um significativo aumento da produtividade das lavou- 
ras, viabilizam a cultura do arroz de sequeiro em diversos ambientes, sobretudo naqueles de altitudes maiores, como nas áreas de chapada, onde é muito alta a incidência de doenças.

$\mathrm{O}$ alto índice de adoção das novas cultivares de arroz de sequeiro lançadas pela pesquisa em Minas Gerais retrata por si só a eficiência do programa de melhoramento, contudo a quantificação do ganho genético obtido é de grande valia para uma autoavaliação e uma reflexão sobre o mesmo.

Várias metodologias têm sido desenvolvidas para estimar o ganho genético e entre elas podem-se citar a de Vencovsky et al. (1988), a de Rodrigues (1990) e a de Soares (1992). Entretanto, tais metodologias apresentam algumas deficiências, principalmente no tocante à menor precisão das estimativas ou a exigência, em certos casos, de testemunhas comuns a todos os anos para estimação da variação ambiental. Breseghello (1995) desenvolveu uma nova metodologia utilizando médias ajustadas. Esse método é bastante eficiente e versátil diante de dados desbalanceados e não exige testemunhas-padrão.

O presente trabalho visou estimar o progresso genético alcançado com o programa de melhoramento de arroz de sequeiro desenvolvido em Minas Gerais, no período de 1974 a 1995, baseando-se no método das médias ajustadas, utilizando as informações obtidas dos ensaios comparativos avançados de cultivares e linhagens de arroz.

\section{MATERIAL E MÉTODOS}

A estimativa do ganho genético foi obtida com base nos resultados dos ensaios comparativos avançados de cultivares e linhagens de arroz de sequeiro conduzidos em Minas Gerais, no período de 1974/75 a 1994/95. Nos ensaios, anualmente, um grupo de cultivares ou linhagens que não têm um bom desempenho são descartadas e substituídas por outras.

O número de ensaios por ano agrícola variou de dois a sete, totalizando 96 , os quais foram conduzidos em delineamento de blocos ao acaso, com quatro repetições nos ensaios de 1974/75 a 1992/93, e três repetições nos dois últimos anos agrícolas. Os dados utilizados são as médias de produtividade de grãos das linhagens e cultivares em cada ano. Essas médias são repetidas $\mathrm{k}$ vezes em relação a cada genótipo, em função do número de ensaios e o número de repetições de cada ano.
O ganho genético foi estimado separadamente nos genótipos precoces e nos de ciclo médio. Tal procedimento deveu-se ao fato de o arroz de sequeiro ser totalmente dependente da água das chuvas, e como elas ocorrem irregularmente podem favorecer ou prejudicar mais intensamente um desses grupos de materiais.

Entre os materiais precoces, as linhagens do primeiro ano agrícola (1974/75) foram as mesmas do ano seguinte (1975/76), por isso as médias desses dois anos foram apresentadas como se fossem um único ano $(1974 / 76)$ e foram agrupados com o terceiro ano agrícola (1976/77), formando o primeiro par de anos (1974/76-76/77). O mesmo ocorreu entre o quinto $(1978 / 79)$ e sexto anos agrícolas (1979/80), originando a denominação 1978/80. Entre os materiais de ciclo médio, as linhagens foram as mesmas no quinto e sexto anos, sendo representados pelo ano 1978/80.

Inicialmente, realizou-se a análise conjunta, segundo o modelo matemático simplificado:

$\mathrm{Y}_{\mathrm{ijr}}=\mu+\mathrm{A}_{\mathrm{j}}+\mathrm{G}_{\mathrm{i}}+\mathrm{E}_{\mathrm{ijr}}$

onde:

$\mathrm{Y}_{\mathrm{ijr}}$ : r-ésima repetição da média do genótipo i no ano j

$\left(\mathrm{r}_{\mathrm{j}}=1, \ldots, \mathrm{s}_{\mathrm{j}}\right)$;

$\mu$ : constante associada à média $\mathrm{y}_{\mathrm{ij}}$;

$A_{j}$ : efeito do ano $j(j=1, \ldots, a)$, fator aleatório;

$\mathrm{G}_{\mathrm{i}}$ : efeito do genótipo $\mathrm{i}(\mathrm{i}=1, \ldots, \mathrm{n})$;

$\mathrm{E}_{\mathrm{ijr}}$ : resíduo do modelo simplificado, com os seguintes componentes:

$\mathrm{GA}_{\mathrm{ij}}$ : efeito da interação genótipo i x ano j;

$\mathrm{e}_{\mathrm{ijr}}$ : erro associado à r-ésima repetição da média $\mathrm{y}_{\mathrm{ij}}$.

Sendo $\mathrm{y}_{\mathrm{ijr}}=\mathrm{y}_{\mathrm{ijr}}$, a soma de quadrados (SQ) relativa ao $\mathrm{e}_{\mathrm{ijr}}$ é nula. Conseqüentemente, a $\mathrm{SQ}$, dado o resíduo da análise de variância, conforme o modelo simplificado adotado, corresponde à SQ da interação GxA, mas os respectivos graus de liberdade encontram-se inflacionados pela repetição, $\mathrm{s}_{\mathrm{j}}$, das médias $\mathrm{y}_{\mathrm{ij}}$. Diante do exposto, o quadrado médio (QM) da interação GxA foi obtido dividindo-se a SQ do resíduo da análise de variância por $\sum_{\mathrm{k}=1}^{\mathrm{a}} \mathrm{n}_{\mathrm{k}}-\mathrm{n}-\mathrm{a}+1$, que corresponde aos graus de liberdade da referida interação $\left(n_{k}\right.$ : número de genótipos avaliados no ano k, e n: número total de genótipos avaliados).

É importante salientar que se se considerasse a interação do modelo (desbalanceado), as médias de genótipos (efeito principal) se tornariam funções não estimáveis (Searle, 1971), uma vez que os genótipos não foram avaliados em todos os anos.

A análise de variância foi feita utilizando-se o procedimento GLM (Modelo Linear Generalizado) do SAS (1985), o qual fornece, se convenientemente exigido, a matriz $\left(\mathrm{X}^{\prime} \mathrm{X}\right)^{-1}$ e o vetor de soluções $\theta^{\circ}$. 
O vetor de médias dos genótipos ajustadas para efeito de ano, produto da análise, é obtido por:

$\hat{\mathrm{Y}}=\mathrm{A} \theta^{\mathrm{o}}$

$\hat{\wedge}$

$\mathrm{Y}$ : vetor das médias de genótipos ajustadas para ano;

$\tilde{\mathrm{A}}$ : matriz de coeficientes com dimensões $n_{\mathrm{k}} \mathrm{x}\left(1+\mathrm{a}+\mathrm{n}_{\mathrm{k}}\right)$;

$\theta^{\circ}$ : vetor de soluções fornecido pelo GLM.

$\mu$-------- anos
$A=\left[\begin{array}{cccccccccccc}1 & 1 / a & 1 / a & . & . & 1 / a & 1 & 0 & . & . & . & 0 \\ . & . & . & . & . & . & . & 1 & . & . & . & 0 \\ . & . & . & . & . & . & . & . & 1 & . & . & 0 \\ . & . & . & . & . & . & . & . & . & . & . & . \\ 1 & 1 / a & 1 / a . & . & . & 1 / a & 0 & 0 & 0 & . & . & 1\end{array}\right]$

A matriz de covariância das médias de genótipos ajustadas para efeito de ano foi encontrada a partir da equação:

$\wedge \wedge$

$\mathrm{V}(\mathrm{Y})=\mathrm{A} \cdot \theta^{\mathrm{o}} \cdot \mathrm{A}^{\mathrm{\prime}} \cdot \mathrm{Q} \mathrm{M}_{\mathrm{GA}}$

sendo $\mathrm{QM}_{\mathrm{GA}}$ o quadrado médio da interação GxA.

Para obtenção da estimativa do ganho genético, foi usada a metodologia das médias ajustadas proposta por Breseghello (1995). Utilizando o vetor de médias ajustadas $(\hat{\text { Y }})$, obtiveram-se as médias dos grupos de genótipos que constituíam os ensaios de cada ano, mas considerando todas as observações disponíveis no período de avaliação, por:

$\hat{\mathrm{Y}}^{*}=\mathrm{S} . \hat{\mathrm{Y}}$

onde,

S: matriz auxiliar, com dimensão a x n, em que cada linha refere-se ao ano j e cada coluna ao genótipo i. Se o genótipo i participa no ano $\mathrm{j}$, a célula ji é preenchida com o inverso do número de genótipos testados no ano $\mathrm{j}$; se não participa, o valor da célula é zero.

A matriz de covariâncias das médias relativas aos grupos de genótipos foi obtida pela equação:

$\wedge \wedge$ $\mathrm{V}\left(\tilde{\mathrm{Y}}^{*}\right)=\mathrm{S} . \tilde{\mathrm{Y}}^{\mathrm{Y}} \cdot \mathrm{S}^{\prime} \cdot \mathrm{QM} \mathrm{QA}_{\mathrm{GA}}$

A seguir foram estimados o vetor de ganhos observados ( G obs ) entre dois grupos consecutivos e a matriz de covariância entre esses mesmos ganhos, $\hat{V}(\mathrm{Gobs})$, respectivamente, por

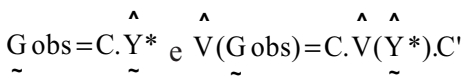

onde $\mathrm{C}$ é uma matriz que possui -1 na diagonal principal e 1 na primeira diagonal superior, sendo o restante preenchido com zero.

Dispondo de Gobs e $\hat{V}(\mathrm{Gobs})$, procedeu-se a estimação do ganho genético médio anual $\left(\mathrm{G}_{\mathrm{m}}\right)$ pelo método dos quadrados mínimos generalizados:

$\mathrm{Gm}=\left(\mathrm{X}^{\prime} \cdot \hat{\mathrm{V}}_{\mathrm{Gobs}}^{-1} \cdot \mathrm{X}\right)^{-1} \cdot \mathrm{X}^{\prime} \cdot \hat{\mathrm{V}}_{\mathrm{Gobs}}^{-1} \cdot \underset{\sim}{\mathrm{G} o b s}$

em que $\mathrm{X}$ é um vetor coluna de 1's. Pode-se demonstrar que $\left(\mathrm{x}^{\prime} \mathrm{v}_{\mathrm{Gobs}}^{-1} \mathrm{x}\right)^{-1}$ é um estimador da variância de GM.

\section{RESULTADOS E DISCUSSÃO}

\section{Genótipos precoces}

As médias de produtividade de grãos ajustadas para efeito de ano para todas as cultivares e linhagens precoces de arroz de sequeiro avaliadas nos ensaios comparativos avançados de Minas Gerais, no período de 1974/75 a 1994/95 são mostradas na Tabela 1. Embora o caráter produtividade de grãos isoladamente não seja determinante na seleção e lançamento de novas cultivares, Guarani, Rio Doce e Douradão, lançadas respectivamente em 1987, 1989 e 1991, estão entre os genótipos mais produtivos no período em estudo. Isso indica que a pesquisa foi eficiente em selecionar e lançar cultivares que agregassem produtividade a outras características de interesse, como resistência a doenças, qualidade de grãos.

A amplitude de variação da produtividade de grãos após o ajustamento das médias (558 a $2.894 \mathrm{~kg} / \mathrm{ha}$ ) indica que os programas de melhoramento de arroz de sequeiro foram eficientes em criar variabilidade genética, possibilitando a seleção das mais favoráveis. A 'Catetão', obtida por coleta em 1981, em Patrocínio, MG, e incluída na rede de ensaios avançados do mesmo ano, mostrou ter um bom potencial de produção. Fica evidente, portanto, que os melhoristas não devem desprezar os genótipos tradicionais, porque mesmo que não venham a se constituir em novas cultivares, são importantes para os programas de hibridação.

$\mathrm{Na}$ Tabela 2 estão relacionadas as estimativas do ganho genético anual e o acumulado em quilogra-

Pesq. agropec. bras., Brasília, v.34, n.3, p.415-424, mar. 1999 
TABELA 1. Médias de produtividade de grãos, ajustadas para efeito de ano, obtidas das cultivares e linhagens precoces de arroz de sequeiro, avaliadas em Minas Gerais, no período de 1974/75 a 1994/95.

\begin{tabular}{llllll}
\hline $\begin{array}{l}\text { Cultivar e } \\
\text { linhagem }\end{array}$ & $\begin{array}{c}\text { Produtividade } \\
\text { de grãos } \\
(\mathrm{kg} / \mathrm{ha})\end{array}$ & $\begin{array}{l}\text { Cultivar e } \\
\text { linhagem }\end{array}$ & $\begin{array}{c}\text { Produtividade } \\
\text { de grãos } \\
(\mathrm{kg} / \mathrm{ha})\end{array}$ & $\begin{array}{c}\text { Cultivar e } \\
\text { linhagem }\end{array}$ & $\begin{array}{c}\text { Produtividade } \\
\text { de grãos } \\
(\mathrm{kg} / \mathrm{ha})\end{array}$ \\
\hline CNA 6974 & $2.893,74$ & L 80-76 & $2.445,67$ & CNA 8069 & $2.053,70$ \\
CNA 7013-D & $2.818,59$ & GA 4166 & $2.442,19$ & CNA 762260 & $2.042,93$ \\
CNA 7119 & $2.804,42$ & GA 4221 & $2.436,14$ & IAC 1337 & $2.038,70$ \\
A8-204-1-1 & $2.787,37$ & GA 4111 & $2.419,16$ & IAC - 25 & $2.034,81$ \\
IAC 87-25 & $2.759,74$ & Catetão & $2.381,35$ & CNA 762069 & $2.022,71$ \\
CNA 6682 & $2.759,49$ & IAC 1323 & $2.376,70$ & CNA 791059 & $2.019,87$ \\
CNA 6710 & $2.738,74$ & A 8-394 & $2.338,54$ & IAC 1176 & $2.015,60$ \\
Guarani & $2.703,57$ & CNA 7458 & $2.318,71$ & IAC 1365 & $2.005,70$ \\
CNA 5166-P & $2.662,03$ & CNA 7728 & $2.317,13$ & TOX 502 & $1.992,28$ \\
CNA 6688 & $2.598,04$ & CNA 8055 & $2.290,70$ & GA 4161 & $1.988,14$ \\
Rio Doce & $2.579,37$ & IAC 165 & $2.289,23$ & CNA 7890 & $1.970,71$ \\
Douradão & $2.577,84$ & IAC 201 & $2.270,73$ & L 45 & $1.934,28$ \\
GA 4123 & $2.571,41$ & CNA 8075 & $2.239,70$ & D. Precoce & $1.898,12$ \\
L 81-55 & $2.568,05$ & IAC 164 & $2.235,62$ & Batatais & $1.840,38$ \\
A8-232 & $2.567,26$ & CNA 067 & $2.233,24$ & P. precoce & $1.781,95$ \\
A8-204-1 & $2.560,76$ & CNA 8070 & $2.221,70$ & CNA 762341 & $1.780,28$ \\
CNA 6674 & $2.542,27$ & L 80-64 & $2.214,24$ & CNA 762310 & $1.742,28$ \\
CNA 5633 & $2.540,04$ & IAC 150 & $2.199,04$ & CNA 790954 & $1.690,28$ \\
CNA 6687 & $2.517,71$ & IAC 25-91 & $2.175,56$ & CNA 791024 & $1.628,28$ \\
GA 4136 & $2.510,14$ & CNA 7864 & $2.162,71$ & IAC 1179 & $1.618,59$ \\
GA 4180 & $2.510,10$ & CNA 7451 & $2.159,71$ & IAC 114 & $1.547,28$ \\
CNA 5628 & $2.508,05$ & IAC 1175 & $2.158,59$ & CNA 6184 & $1.431,33$ \\
Tangará & $2.507,60$ & GA 4209 & $2.125,14$ & IRAT 335 & $1.384,59$ \\
CNA 7681 & $2.453,17$ & L 50 & $2.087,48$ & Belle Patna & 558,04 \\
L 80-63 & $2.450,18$ & CNA 7892 & $2.080,71$ & & \\
\hline Média & & & & & $2.239,10$ \\
\hline
\end{tabular}

mas por hectare e em porcentagem, em relação à média dos genótipos no primeiro ano, entre os diferentes pares de anos e o ganho genético médio em todo o período (1974/95). Observa-se que o ganho genético anual foi de magnitude bastante variável, oscilando de $427,44 \mathrm{~kg} / \mathrm{ha}$ a $-424,38 \mathrm{~kg} / \mathrm{ha}$. Os ganhos genéticos negativos indicam que em determinados pares de anos houve um retrocesso na substituição dos genótipos descartados. Embora isso não seja esperado, é possível ocorrer, pois a seleção e descarte de materiais não é baseada apenas na produtividade de grãos. Um exemplo claro foi o ganho negativo de $-424,38 \mathrm{~kg} / \mathrm{ha}$ ocorrido entre os pares de anos 1990/91 e 1991/92. Em 1990/91, participaram diversas linhagens com alto potencial de rendimento, entre elas a CNA 6974, IAC 87-25, CNA 6682,
CNA 6688, A8-204-1, CNA 6674 e a Tangará (Tabela 1). Entretanto, todas foram descartadas quando avaliada a qualidade de grãos, acarretando um ganho genético negativo bastante alto no ano seguinte, uma vez que foram substituídas por linhagens de menor rendimento de grãos, porém, supostamente, com melhor qualidade de grãos.

Quanto ao ganho genético anual acumulado, notase que foi crescente até o ano agrícola 1990/91, a partir do qual apresentou ligeira redução. Cabe esclarecer, todavia, que em meados da década de 80 , o arroz de sequeiro passou a sofrer intensa concorrência do arroz longo fino (agulhinha) de melhor qualidade culinária, produzido em condições de arroz irrigado por inundação controlada. A preferência do consumidor e o maior preço de mercado do arroz 
TABELA 2. Estimativas de ganho genético anual em relação à média dos genótipos no primeiro ano, e ganho genético anual acumulado entre pares de ano, em genótipos precoces.

\begin{tabular}{lccccc}
\hline Pares de anos & $\begin{array}{c}\text { Ganho genético } \\
\text { anual } \\
(\mathrm{kg} / \mathrm{ha})\end{array}$ & $\begin{array}{c}\text { Ganho/ } \\
\text { desvio-padrão }\end{array}$ & $\begin{array}{c}\text { Ganho genético } \\
\text { anual }(\%)\end{array}$ & $\begin{array}{c}\text { Ganho genético } \\
\text { anual acumulado } \\
(\mathrm{kg} / \mathrm{ha})\end{array}$ & $\begin{array}{c}\text { Ganho genético } \\
\text { anual acumulado } \\
(\%)\end{array}$ \\
\hline $74 / 76-76 / 77$ & 427,4444 & 3,572 & 22,67 & 427,4444 & 22,67 \\
$76 / 77-77 / 78$ & 199,6913 & 1,897 & 10,59 & 627,1353 & 33,26 \\
$77 / 78-78 / 80$ & $-37,4574$ & $-1,621$ & $-1,99$ & 589,6779 & 31,27 \\
$78 / 80-80 / 81$ & 21,2731 & 0,747 & 1,13 & 610,9509 & 32,40 \\
$80 / 81-81 / 82$ & 44,5858 & 1,942 & 2,36 & 655,5368 & 34,76 \\
$81 / 82-82 / 83$ & $-163,5270$ & $-1,567$ & $-8,67$ & 492,0098 & 26,09 \\
$82 / 83-83 / 84$ & 257,7119 & 3,688 & 13,67 & 749,7217 & 39,76 \\
$83 / 84-84 / 85$ & 140,0639 & 1,942 & 7,43 & 889,7856 & 47,76 \\
$84 / 85-85 / 86$ & 119,7908 & 2,977 & 6,35 & $1.009,5764$ & 53,54 \\
$85 / 86-86 / 87$ & $-6,5404$ & $-0,169$ & $-0,35$ & $1.003,0360$ & 53,19 \\
$86 / 87-87 / 88$ & 10,1666 & 0,318 & 0,54 & $1.013,2027$ & 53,73 \\
$87 / 88-88 / 89$ & $-107,6350$ & $-2,150$ & $-5,71$ & 905,5677 & 48,02 \\
$88 / 89-89 / 90$ & 260,2000 & 4,976 & 13,80 & $1.165,7677$ & 61,82 \\
$89 / 90-90 / 91$ & 32,4327 & 0,858 & 1,72 & $1.198,2004$ & 63,54 \\
$90 / 91-91 / 92$ & $-424,3750$ & $-3,321$ & $-22,50$ & 773,8254 & 41,04 \\
$91 / 92-92 / 93$ & 316,0317 & 2,343 & 16,76 & $1.089,8571$ & 57,80 \\
$92 / 93-93 / 94$ & $-241,1900$ & $-2,167$ & $-12,79$ & 848,6671 & 45,01 \\
$93 / 94-94 / 95$ & 11,2693 & 0,071 & 0,60 & 859,9364 & 45,61 \\
\hline Ganho genético médio anual (kg/ha) & & & & $23,82 \pm 5,05$ \\
Ganho genético médio anual (\%) & & & & $1,26{ }^{*}$ ( \\
\hline
\end{tabular}

${ }^{1}$ Valores acima de 2 desvios-padrão são considerados estatisticamente significativos (El-Rouby et al., 1973).

** Significativo a $1 \%$ de probabilidade.

agulhinha levaram os melhoristas de arroz de sequeiro a darem um novo direcionamento aos programas de melhoramento, estabelecendo como prioridade a qualidade física e química de grãos. Certamente que as linhagens obtidas a partir de então não tiveram a mesma pressão de seleção no quesito produtividade de grãos, uma vez que aquelas que possuíam grãos de boa qualidade eram selecionadas em detrimento de maior potencial produtivo.

Os ganhos ou perdas genéticas (Tabela 2) observados foram positivamente significativos entre os pares de anos 74/76-76/77, 82/83-83/84, 84/85-85/86, $88 / 89-89 / 90$ e $91 / 92-92 / 93$. Por outro lado, entre os pares de ano 87/88-88/89, 90/91-91/92 e 92/93-93/94 os ganhos foram negativos e estatisticamente significativos. O ganho genético médio no período total envolvido no estudo (1974/75 a 1994/95) foi de $23,82 \pm 5,05 \mathrm{~kg} / \mathrm{ha}$, o qual redundou em um ganho médio de $1,26 \%$ altamente significativo.
A partir do ganho médio anual (Gma), pôde-se estimar o ganho genético total (GT) no período, ou seja, o GT $=$ Gma (a-1), sendo a o número de anos. Assim, obteve-se GT $=476,4 \mathrm{~kg} / \mathrm{ha}$. Tomando-se a média de produtividade de grãos de arroz de sequeiro no Estado, que oscila em torno de $1.200 \mathrm{~kg} / \mathrm{ha}$ (Minas Gerais, 1995), o incremento de $476,4 \mathrm{~kg} / \mathrm{ha}$, por meio do melhoramento genético, em 21 anos de pesquisa, foi de grande expressão. A performance do programa de melhoramento de arroz de sequeiro em Minas Gerais pode ser avaliada, também, comparando-a com os resultados obtidos com o arroz de sequeiro no Paraná, no período de 1975 a 1989, que foi de 1,35\% (Abbud, 1991), com o do arroz irrigado no Nordeste, de $0,77 \%$ (Breseghello, 1995), e com o do arroz irrigado no Espírito Santo, no período de 1983/84 a 1994/95, de 2,68\% (Silva, 1996). Cabe esclarecer, todavia, que, à exceção de Breseghello (1995), os demais autores utilizaram o método dos quadra- 
dos mínimos ponderados, sem o ajustamento das médias.

Dos 2.775 contrastes possíveis, apenas 4,32\% mostraram-se estatisticamente significativos, e destes, somente os 23,3 \% de maior interesse estão apresentados na Tabela 3. A maioria dos contrastes significativos envolvem as cultivares, isso porque elas foram avaliadas inúmeras vezes, por serem utilizadas como testemunhas. Dessa forma, aumenta-se a precisão experimental, possibilitando a detecção da significância. Observa-se pela Tabela 3 que as cultivares Rio Doce, Guarani e Douradão foram as que apresentaram maior número de contrastes significativos, superando diversos materiais, destacando-se entre eles as cultivares mais antigas, como a Pratão Precoce, IAC 25, IAC 164 e Dourado Precoce. A CNA 7119 e CNA 8070 superaram estatisticamente apenas a Belle Patna; contudo esses materiais foram avaliados apenas em um ano agrícola.

\section{Genótipos de ciclo médio}

Os resultados de médias de produtividade de grãos ajustadas para efeito de ano nas 70 cultivares e linhagens de ciclo médio avaliadas são apresentados na Tabela 4. À semelhança do ocorrido com as cultivares do grupo precoce, a pesquisa foi eficiente em identificar, entre as linhagens de ciclo médio, aquelas que agregassem potencial de rendimento de grãos a outras características de interesse. As cultivares Rio Paranaíba, Caiapó e Canastra, lançadas respectivamente em 1986, 1992 e 1996, estão entre os nove genótipos mais produtivos. A cultivar Confiança, também lançada em 1996, não se encontra entre as de maior rendimento de grãos, mas possui grãos de classe longo fino, de excepcional qualidade culinária, assemelhando-se ao tipo agulhinha do arroz irrigado. Esta característica lhe confere maior preço de mercado, compensando sua menor produtividade.

As cultivares IAC 1205 e IAC 1204, que possuem alto grau de parentesco (linhagens irmãs), destacaram-se como as de maior potencial de produtividade de grãos entre todos os materiais avaliados. Não foram, contudo, lançadas como novas cultivares para Minas Gerais, porque são suscetíveis à Pyricularia grisea Steud., causadora da brusone. Como o Estado é freqüentemente submetido a intensos veranicos, que aumentam a suscetibilidade do arroz a essa enfermidade, seria de alto risco o plantio das cultivares (Prabhu, 1980). A constatação de que os dois materiais mais produtivos, nos 21 anos estudados, são suscetíveis à brusone, principal doença do arroz, deixa dúvida quanto à intensa seleção que se exerce sobre a enfermidade, descartando qualquer material que se mostre suscetível ou moderadamente suscetível. Supõe-se que essa informação deva merecer cuidados na elaboração de programas de melhoramento dessa espécie.

As estimativas do ganho genético anual e acumulado, em quilogramas por hectare e em porcentagem (relativas à média dos genótipos no primeiro ano), e do ganho genético médio, em todo o período (21 anos), são mostrados na Tabela 5. Nota-se que

TABELA3. Contrastes significativos entre as médias ajustadas de algumas cultivares e linhagens de ciclo precoce.

\begin{tabular}{lcccccccc}
\hline $\begin{array}{l}\text { Cultivar e } \\
\text { linhagem }\end{array}$ & $\begin{array}{c}\text { Belle } \\
\text { Patna }\end{array}$ & $\begin{array}{c}\text { IAC } \\
114\end{array}$ & $\begin{array}{c}\text { CNA } \\
791024\end{array}$ & $\begin{array}{c}\text { CNA } \\
790954\end{array}$ & $\begin{array}{c}\text { Pratão } \\
\text { Precoce }\end{array}$ & D. Precoce & IAC 25 & IAC 164 \\
\hline CNA 7119 & $2.372,1$ & & & & & & & \\
Guarani & $2.145,5$ & $1.156,3$ & $1.075,3$ & $1.013,3$ & 921,6 & 805,4 & 668,8 & 467,9 \\
Rio Doce & $2.021,3$ & $1.031,1$ & & & 797,4 & 681,3 & 544,6 & \\
Douradão & $2.019,8$ & $1.030,6$ & & & 795,9 & 679,7 & 543,0 & 342,2 \\
GA 4123 & $2.013,4$ & & & & 789,5 & & 536,6 & \\
Catetão & $1.823,3$ & & & & & & & \\
IAC 165 & $1.731,2$ & & & & & & & \\
IAC 164 & $1.677,6$ & & & & & & & \\
CNA 8070 & $1.663,7$ & & & & & & & \\
D. Precoce & $1.340,1$ & & & & & & & \\
\hline
\end{tabular}


os ganhos anuais variaram de $318,65 \mathrm{~kg} / \mathrm{ha}$ a $-81,06 \mathrm{~kg} / \mathrm{ha}$, ou seja, uma variação menor que a observada no grupo precoce. É interessante ressaltar que os ganhos entre os pares de anos 74/7575/76, 76/77-77/78, 78/80-80/81, 86/87-87/88 e 93/94$94 / 95$ foram positivos e significativos $(\mathrm{P} \leq 0,01)$, e que para o par de anos 92/93-93/94 o ganho foi negativo e significativo. Observando o ganho genético acumulado, constata-se que houve uma tendência a aumentar até o ano agrícola de 1989/90; a partir de então se estabilizou e somente no último ano voltou a crescer. Esse resultado corrobora o obtido com o grupo precoce, e que na década de 90 a prioridade de seleção foi qualidade de grãos, em detrimento da produtividade de grãos.

O ganho genético médio anual, no período avaliado foi de $46,43 \pm 7,31 \mathrm{~kg} / \mathrm{ha}$, gerando um ganho mé- dio de 3,37\%. A partir do ganho médio anual, estimou-se o ganho total, que foi de $928,6 \mathrm{~kg} / \mathrm{ha}$, ou seja, o equivalente a $77 \%$ da produtividade média de arroz de sequeiro no Estado.

Como se observa, o ganho genético médio do grupo de ciclo médio $(3,37 \%)$ foi mais que o dobro do observado no grupo precoce $(1,26 \%)$. Uma das causas é que, no primeiro ano, a média dos materiais precoces $(1.885,7 \mathrm{~kg} / \mathrm{ha})$ foi superior à dos de ciclo médio $(1.376,6 \mathrm{~kg} / \mathrm{ha})$, afetando diretamente as estimativas do ganho médio percentual. Outra causa é a de que ocorreu realmente um maior ganho genético entre os materiais do grupo de ciclo médio, ocasionado provavelmente pela maior tolerância dos novos materiais às doenças, sobretudo à brusone, obtida principalmente pelo cruzamento de genótipos brasileiros com africanos. Embora esse ganho tenha

TABELA 4. Médias de produtividade de grãos, ajustadas para efeito de ano obtidas com as cultivares e linhagens de ciclo médio de arroz de sequeiro, avaliadas em Minas Gerais, no período de 1974/75 a $1994 / 95$.

\begin{tabular}{lllclc}
\hline $\begin{array}{l}\text { Cultivar e } \\
\text { linhagem }\end{array}$ & $\begin{array}{c}\text { Produtividade } \\
\text { de grãos } \\
(\mathrm{kg} / \mathrm{ha})\end{array}$ & \multicolumn{1}{c}{$\begin{array}{c}\text { Cultivar e } \\
\text { linhagem }\end{array}$} & $\begin{array}{c}\text { Produtividade de } \\
\text { grãos } \\
(\mathrm{kg} / \mathrm{ha})\end{array}$ & $\begin{array}{c}\text { Cultivar e } \\
\text { linhagem }\end{array}$ & $\begin{array}{c}\text { Produtividade de } \\
\text { grãos } \\
(\mathrm{kg} / \mathrm{ha})\end{array}$ \\
\hline IAC 1205 & $3.196,92$ & IAC 76-49 & $2.046,00$ & CNA 108-B... & $1.768,00$ \\
IAC 1204 & $2.947,92$ & CNA 104-B... & $2.040,32$ & M2-47 & $1.761,12$ \\
Canastra & $2.593,77$ & Cabaçu & $2.034,29$ & GA 5176 & $1.751,86$ \\
Rio Paranaíba & $2.427,95$ & Progresso & $2.027,92$ & CNA 117-B... & $1.750,00$ \\
CNA 7691 & $2.384,52$ & CNA 7911 & $2.002,46$ & CNA 6881 & $1.703,22$ \\
L 141 & $2.365,92$ & CNA 7057 & $1.981,85$ & CNA 6892 & $1.684,22$ \\
CNA 7024 & $2.357,02$ & GA 4146 & $1.954,84$ & IAC 1246 & $1.667,23$ \\
CNA 7677 & $2.327,52$ & CNA 7630 & $1.950,85$ & IAC 1131 & $1.652,89$ \\
Caiapó & $2.295,22$ & IAC 47-72 & $1.939,51$ & CNA 6681 & $1.651,80$ \\
GA 4143 & $2.291,58$ & GA 4145 & $1.934,85$ & CNA 7876 & $1.633,22$ \\
CNA 8096 & $2.279,92$ & CNA 7066 & $1.931,85$ & IAC 136 & $1.624,77$ \\
CNA092-BM... & $2.260,00$ & IAC 1335 & $1.919,22$ & CNA 7462 & $1.583,22$ \\
CNA 7657 & $2.239,35$ & CNA 6843-1 & $1.916,39$ & IAC 5100 & $1.555,32$ \\
GA 4107 & $2.175,86$ & CNA 6968 & $1.895,85$ & IAC 5544 & $1.510,47$ \\
GA 4116 & $2.163,86$ & M1-47 & $1.892,12$ & IAC 5154 & $1.466,59$ \\
L 291 & $2.158,92$ & IAC 47 & $1.861,74$ & CNA 104-B2... & $1.372,77$ \\
CNA 104-B.. & $2.153,77$ & CNAx 104-B... & $1.855,77$ & Bico Ganga & $1.278,62$ \\
IAC 1333 & $2.148,22$ & Cuiabana & $1.813,25$ & IP-SL-562 & 948,29 \\
CNA 6981 & $2.142,80$ & IAC 5128 & $1.810,63$ & IP-SL-162 & 934,31 \\
CNA 7690 & $2.138,92$ & IAC 5032 & $1.809,20$ & DP x AC & 791,09 \\
CNA 6975-2 & $2.133,46$ & Araguaia & $1.806,20$ & DP X 90C & 438,09 \\
CNA 7877 & $2.085,22$ & IAC 78-19 & $1.801,00$ & IPEACO 569 & 138,09 \\
Confiança & $2.065,06$ & CNA 7726 & $1.798,52$ & & \\
CNA 6966 & $2.051,80$ & CNA 7460 & $1.777,22$ & & \\
\hline Média & & & & & $1.883,60$ \\
\hline
\end{tabular}


TABELA 5. Estimativas de ganho genético anual em relação à média dos genótipos no primeiro ano, e ganho genético anual acumulado, entre pares de ano, em genótipos de ciclo médio.

\begin{tabular}{|c|c|c|c|c|c|}
\hline Pares de anos & $\begin{array}{c}\text { Ganho } \\
\text { genético anual } \\
(\mathrm{kg} / \mathrm{ha})\end{array}$ & $\begin{array}{c}\text { Ganho/ } \\
\text { desvio-padrão }\end{array}$ & $\begin{array}{c}\text { Ganho genético } \\
\text { anual } \\
(\%)\end{array}$ & $\begin{array}{c}\text { Ganho genético } \\
\text { anual acumulado } \\
(\mathrm{kg} / \mathrm{ha})\end{array}$ & $\begin{array}{c}\text { Ganho genético } \\
\text { anual acumulado } \\
(\%)\end{array}$ \\
\hline $74 / 75-75 / 76$ & 306,94 & 3,954 & 22,30 & 306,944 & 22,30 \\
\hline $75 / 76-76 / 77$ & 101,57 & 1,694 & 7,38 & 408,517 & 29,68 \\
\hline 76/77-77/78 & 225,60 & 2,841 & 16,39 & 634,118 & 46,07 \\
\hline $77 / 78-78 / 80$ & $-16,82$ & $-0,491$ & $-1,22$ & 617,301 & 44,85 \\
\hline $78 / 80-80 / 81$ & 168,32 & 2,113 & 12,23 & 785,625 & 57,08 \\
\hline $80 / 81-81 / 82$ & 8,35 & 0,059 & 0,61 & 793,978 & 57,69 \\
\hline $81 / 82-82 / 83$ & $-46,14$ & $-0,222$ & $-3,35$ & 747,839 & 54,34 \\
\hline $82 / 83-83 / 84$ & 176,89 & 1,19 & 12,85 & 924,734 & 67,19 \\
\hline $83 / 84-84 / 85$ & 57,36 & 0,39 & 4,17 & 982,096 & 71,36 \\
\hline $84 / 85-85 / 86$ & $-36,15$ & $-0,549$ & $-2,63$ & 945,945 & 68,73 \\
\hline $85 / 86-86 / 87$ & $-38,30$ & $-0,753$ & $-2,78$ & 907,641 & 65,95 \\
\hline $86 / 87-87 / 88$ & 130,71 & 2,100 & 9,50 & $1.038,351$ & 75,45 \\
\hline $87 / 88-88 / 89$ & 46,81 & 1,584 & 3,40 & $1.085,157$ & 78,85 \\
\hline $88 / 89-89 / 90$ & 40,17 & 1,229 & 2,92 & $1.125,326$ & 81,77 \\
\hline $89 / 90-90 / 91$ & $-81,06$ & $-0,739$ & $\begin{array}{r}2,50 \\
-5,89\end{array}$ & $1.044,269$ & 75,88 \\
\hline 90/91-91/92 & $-33,06$ & $-0,222$ & $-2,40$ & $1.011,205$ & 73,48 \\
\hline $91 / 92-92 / 93$ & 156,05 & 1,193 & 11,34 & $1.167,253$ & 84,82 \\
\hline $92 / 93-93 / 94$ & $-228,37$ & $-2,317$ & $-16,59$ & 938,887 & 68,23 \\
\hline $93 / 94-94 / 95$ & 318,65 & 4,112 & 23,15 & $1.257,542$ & 91,38 \\
\hline \multirow{2}{*}{\multicolumn{3}{|c|}{ Ganho genético médio anual $(\mathrm{kg} / \mathrm{ha})$}} & & & $46,43 \pm 7,31$ \\
\hline & & & & & $3,37^{* *}$ \\
\hline
\end{tabular}

** Significativo a $1 \%$ de probabilidade.

ocorrido também entre os materiais do grupo precoce no tocante à resistência a enfermidades, ele foi sempre atenuado pelo maior escape, que geralmente ocorre nas cultivares e linhagens de ciclo mais curto.

O ganho genético médio percentual de $3,37 \%$ do grupo de ciclo médio chegou até mesmo a superar o ganho médio verificado em outras culturas, como o do milho no Brasil (1964/84), obtido por Vencovsky et al. (1988), que foi de $2,2 \%$ em relação a populações, e $1,7 \%$ a híbridos comerciais; o da soja no Paraná, no período de 1981 a 1986, de 1,8\% em relação aos genótipos de maturação precoce, e de 1,3\% aos semiprecoces (Toledo et al., 1990); o de feijão em Minas Gerais, durante 17 anos (EPAMIG, 1992), que foi de $1,9 \%$; e o do sorgo no Brasil, no período de 1974/75 a 1987/88, de 1,2\% (Rodrigues, 1990).

Entre os materiais de ciclo médio, apenas 140 dos 2.415 contrastes possíveis se revelaram significativos $(\mathrm{P} \leq 0,05)$. Destes, somente os $42,3 \%$ de maior interesse são mostrados na Tabela 6. Os materiais que mais se destacaram foram: IAC 1205 , IAC 1204, Rio Paranaíba, Canastra, Caiapó e CNA 7024, mostrando médias bastante superiores a vários genótipos. Vale ressaltar que a cultivar Canastra foi lançada em 1996 para cultivo em condições de sequeiro tradicional e irrigado por aspersão. A Confiança, lançada junto com a Canastra para os mesmos sistemas de cultivo, embora não esteja entre as mais produtivas, foi superada estatisticamente apenas pela IAC 1205, indicando, portanto, que é uma cultivar com bom potencial de produtividade de grãos.

\section{Grupo precoce X grupo de ciclo médio}

Comparando-se a média geral de produtividade de grãos dos 74 materiais precoces, que foi de $2.239,1 \mathrm{~kg} /$ ha (Tabela 1 ), com os 70 de ciclo médio, de $1.883,6 \mathrm{~kg} / \mathrm{ha}$ (Tabela 4), verifica-se que há uma diferença de $355,5 \mathrm{~kg} / \mathrm{ha}$ em favor do grupo 
precoce, considerada altamente significativa (desvio padrão $=54,18, \log 0355,5 / 54,18=6,56$ ). Esse resultado veio confirmar o que já se supunha, ou seja, em Minas Gerais, os materiais precoces têm propiciado maiores produções que os de ciclo médio, embora estes tenham maior potencial de produtividade de grãos. Na prática, o que tem ocorrido é que os materiais precoces são freqüentemente menos prejudicados por deficiências hídricas, uma vez que, por permanecerem menos tempo no campo, apresentam maior probabilidade de escape de períodos de menor pluviosidade (Morais et al., 1983).

A redução ou estabilização dos ganhos genéticos observados no programa de melhoramento de arroz de sequeiro desenvolvido em Minas Gerais a partir da década de 90 sugere que novas alternativas devem ser empreendidas para aumentar a variabilidade genética, e entre elas podem se destacar a seleção recorrente, o aumento da precisão experimental e o uso de delineamentos estatísticos de melhor controle ambiental, a exemplo do látice.

\section{CONCLUSÕES}

1. O ganho genético médio de $1,26 \%$ em relação aos materiais do grupo precoce, e de $3,37 \%$ em relação aos do grupo médio, obtido no período de 21 anos, indica que o programa de melhoramento genético de arroz de sequeiro desenvolvido em Minas Gerais é bastante eficiente.

2. Os materiais do grupo precoce superam estatisticamente os do grupo de ciclo médio, quanto à produtividade de grãos, indicando que em Minas Gerais a preferência é para o plantio de cultivares de ciclo curto.

\section{AGRADECIMENTOS}

À Fundação de Amparo à Pesquisa no Estado de Minas Gerais (Fapemig) e à Embrapa, pelo financiamento do programa de melhoramento genético do arroz desenvolvido em Minas Gerais.

\section{REFERÊNCIAS}

ABBUD, N.S. Melhoramento genético do arroz de sequeiro (Oryza sativa L.) no estado do Paraná. 
Piracicaba: USP-ESALQ, 1991. 141p. Tese de Doutorado.

BRESEGHELLO, F. Ganhos para produtividade pelo melhoramento genético do arroz irrigado no Nordeste do Brasil. Goiânia: UFG, 1995. 93p. Dissertação de Mestrado.

EL-ROUBY, M.M.; MORAYEM, Y.S.; NAWAR, A.A. Estimation fo genetic variance and its components in maize under stress and non-stress environments. I - Planting date. Egyptian Journal of Genetics and Cytology, v.2, p.10-19, 1973.

MINAS GERAIS. Secretaria do Estado da Agricultura, Pecuária e Abastecimento. Cenário Futuro do Negócio Agrícola de Minas Gerais. Belo Horizonte: EPAMIG, 1995. v.3, 57p.

MORAIS, O.P.; SANT'ANA, E.P.; CATEL, M.; PRABHU, A.S.; CASTRO, E.M. Melhoramento genético voltado para a cultura do arroz de sequeiro. In: FERREIR, M.E.; YAMADA, T.; MALAVOLTA, E. (Eds.). Cultura do arroz de sequeiro: fatores afetando a produtividade. Piracicaba: POTAFOS, 1983. p.145-178.

PRABHU, A.S. Sistemas de produção de arroz de sequeiro visando o controle da brusone. Goiânia: Embrapa-CNPAF, 1980. 15p. (Embrapa-CNPAF. Circular técnica, 1).

PROJETO FEIJÃO: RELATÓRIO 1988/92. Belo Horizonte; EPAMIG, 1992. 135p.
RODRIGUES, J.A.S. Progresso genético e potencial de risco da cultura do sorgo granífero (Sorghum bicolor (L). Moench) no Brasil. Piracicaba: ESALQ, 1990. 17p. Tese de Doutorado.

SAS INSTITUTE. SAS user's guide: statistics. 5.ed. Cary, NC, 1985. 956p.

SEARLE, S.R. Linear models. New York: John Wiley \& Sons, 1971. 532p.

SILVA, A.F. Contribuição do melhoramento genético do arroz irrigado por inundação para rendimento de grãos, no período de $1983 / 84$ a $1994 / 95$, no Estado do Espírito Santo. Lavras: UFLA, 1996. 108p. Tese de Doutorado.

SOARES, A.A. Desempenho do melhoramento genético do arroz de sequeiro e irrigado na década de oitenta em Minas Gerais. Lavras: ESAL, 1992. 188p. Tese de Doutorado.

TOLEDO, J.F.F. de; ALMEIDA, L.A. de; KIIHL, R.A. de S.; MENOSSO, O.G. Ganho genético em soja no estado do Paraná, via melhoramento. Pesquisa Agropecuária Brasileira, Brasília, v.25, n.1, p.8994, jan. 1990.

VENCOVSKY, R.; MORAES, A.R.; GARCIA, J.C.; TEIXEIRA, N.M. Progresso genético em vinte anos de melhoramento de milho no Brasil. In: CONGRESSO NACIONAL DE MILHO E SORGO, 16., 1986, Belo Horizonte. Anais... Sete Lagoas: EmbrapaCNPMS, 1988. p.300-307. 